\title{
AGORA É HORA DE...: PROCESSOS DE ADMINISTRAÇÃO, GESTÃO E REGULAÇÃO DOS TEMPOS, ROTINAS E CORPOS NAS INSTITUIÇÕES DE EDUCAÇÃO INFANTIL
}

\author{
Romilson Martins Siqueira ${ }^{1}$ \\ Luana Ferreira Borges ${ }^{2}$
}

\section{RESUMO}

O presente trabalho se ocupou do estudo das rotinas do sono e do banho em instituições de educação infantil com o objetivo de compreender os processos de construção da identidade corporal das crianças. Os resultados indicaram que estes processos se instauram sob as bases da regulação e não da autonomia. Evidenciaram as precárias condições sob as quais se concretizaram os momentos do sono e do banho, fato que indica que as condições materiais e concretas também determinam a forma como as concepções e práticas institucionais e profissionais conduzem a ação educativa nesta etapa da educação.

Palavras-chave: Regulação. Rotinas. Educação Infantil. Corpos.

\footnotetext{
1 Pós Doutorando pelo Programa de Pós Graduação em Educação da UFG, sob a supervisão do professor Luiz Fernandes Dourado. Doutor e Mestre em Educação pela Faculdade de Educação da UFG. Graduação em Pedagogia pela Pontifícia Universidade Católica de Goiás. Professor do Programa de Pós Graduação em Educação da PUC Goiás. Diretor da Escola de Formação de Professores e Humanidades da PUC Goiás. Coordenador do Grupo de Estudos e Pesquisas sobre Cultura e Educação na Infância. Atua na linha de Pesquisa Educação, Sociedade e Cultura e tem como objeto de estudo os processos educativos e culturais na infância e da criança em contextos da Educação Infantil e em outros espaços institucionais. Orcid iD: http://orcid.org/0000-0002-6878-9373. E-mail: romilsonmartinsiqueira@hotmail.com

2 Mestre em Educação pela PUC Goiás. Graduação em Pedagogia - Faculdades Integradas de Cassilândia (2005). Atua com professora no Ensino Superior nas instituições: Faculdade Sul-Americana e na Faculdade Nossa Senhora Aparecida no curso de Pedagogia. Tem experiência na área de Educação, com ênfase Educação escolar e Formação de professores, atuando principalmente nos seguintes temas: didática, avaliação, práticas educativas, currículo, formação de professores, planejamento, organização e gestão escolar, estrutura e funcionamento da educação, educação infantil entre outros. Orcid iD: http://orcid.org/0000-0003-4319-3423. E-mail: luanaferreiraborges@hotmail.com
} 


\title{
NOW IT'S TIME TO...: ADMINISTRATION, MANAGEMENT AND REGULATION OF
}

\author{
TIMES, ROUTINES AND BODY IN THE CHILDREN'S \\ EDUCATION INSTITUTIONS
}

\begin{abstract}
The present work deals with the study of sleeping and bathing routines in children's education institutions, with the objective of the process of the construction of children's body identity. The results indicated that these processes are established under the basis of regulation and not autonomy. They evidenced how precarious conditions under which the moments of sleeping and bathing are materialized, as an indication of how material and concrete conditions also determine a way as conceptualized, institutional and professional practices led to educational actions in the teaching stage.
\end{abstract}

Keywords: Regulation. Routines. Early Childhood Education. Body.

\section{AHORA ES HORA DE...: PROCEDIMIENTOS DE ADMINISTRACIÓN, GESTIÓN Y REGULACIÓN DE LOS TIEMPOS, ROTINAS Y CUERPOS EN LA INSTITUCIONES DE EDUCACIÓN INFANTIL}

\section{RESUMEN}

El presente trabajo se encargó de estudiar las rutinas del sueño y del baño en instituciones de educación infantil, con el objetivo de comprender los procesos de construcción de la identidad corporal de los niños. Los resultados indicaron que los procesos se instalaron con sumisión a las bases de la regulación y no de la autonomía. Evidenciaron las precarias condiciones en que las cuales se concretizaron en los momentos del sueño y del baño, hecho que indica que las condiciones materiales y concretas también determinan la forma como las concepciones y prácticas institucionales y profesionales conducen la acción educativa en esta etapa de enseñanza.

Palabras clave: Regulación. Rutinas. Educación Infantil. Cuerpos.

\section{PARA COMEÇO DE CONVERSA}

O presente estudo é parte dos resultados de uma pesquisa ${ }^{3}$ realizada em cinco instituições de Educação Infantil de Goiânia e se ocupou da seguinte questão: considerando-se a rotina do banho e do sono como

\footnotetext{
3 Dissertação de Mestrado ligada à Linha de Pesquisa "Educação, Sociedade e Cultura" e
} ao "Grupo de Estudos e Pesquisa sobre Cultura e Educação na Infância" (GEPCEI). 
momentos da ação educativa na Educação Infantil, como se constituem os processos de regulação ou autonomia na identidade corporal das crianças em instituições de Educação Infantil? Os estudos foram elucidados com base no método do Materialismo Histórico Dialético e permeados por teorias críticas que permitiram desvelar as contradições presentes nos aspectos objetivos e subjetivos dos objetos estudados. A metodologia de pesquisa foi conduzida pela observação dos momentos do sono e do banho, em um total de 20 ocorrências, sendo todas relatadas em diário de bordo. Também foram realizadas entrevistas com as professoras responsáveis pelos agrupamentos para apreender a relação entre concepções, teoria e prática. Os resultados desse trabalho indicaram que, durante a rotina do banho e do sono, ficam latentes práticas centradas na figura adulta que orientam, normatizam, regulam e controlam as ações corporais das crianças. Da mesma forma, estas práticas estiveram entrecruzadas por aspectos da gestão e das condições estruturais e físicas sob as quais determinadas práticas eram desempenhadas.

\section{AUTONOMIA E REGULAÇÃO: dialéticas que marcam concepções e práticas}

Um dos aspectos destacados na pesquisa diz respeito às concepções das professoras sobre autonomia e regulação da criança ${ }^{4}$ na rotina da Educação Infantil. A análise que permeia a discussão permite refletir sobre um projeto de educação para libertação ou para alienação. Entende-se que as instituições de ensino, fato que não se restringe apenas ao campo infantil, historicamente têm se ocupado de preparar as crianças para a sociedade. Todavia, essa preparação é pautada a partir de uma lógica de sociedade desigual e pela negação de direitos. Do ponto de vista das condições objetivas, destaca-se uma sociedade marcada pelo viés econômico, instrumental e pragmático.

Para Charlot (2013), a escola desempenha um ato educativo diferente da sociedade global. Se por um lado, ela pode reproduzir padrões e

\footnotetext{
${ }^{4}$ Sobre os estudos das concepções de infância e criança, ver: "Por uma leitura crítica das concepções de infância e criança" - Siqueira (2011).
} 
modelos de sociabilidade, por outro, ainda é possível neste espaço educativo de se pensar a relação dos adultos com as crianças a partir de outras perspectivas para além da regulação. É nesse contexto que as concepções que envolvem a autonomia ou a regulação do corpo da criança estão inseridas no campo de disputa da educação.

Nesse processo, a interação da criança com o adulto é marcada pelo modo como a sociedade concebe o lugar da criança: ou seja, pela fragilidade. Logo, aquilo que deveria se constituir como autonomia nas/das crianças passa a ser marcado pelas orientações e compreensões adultocêntricas para a criança e para o mundo que a cerca. A escola, nesta perspectiva, define-se como instituição educativa que advoga o direito de ensinar um saber legítimo, a partir do qual reafirma muitas ideias e práticas reguladoras. Para Charlot (2013), um dos processos de regulação mais evidente nas escolas e instituições de Educação Infantil refere-se às formas de disciplinamento:

a disciplina é luta cultural contra todas as formas de corrupção que a criança traz em si mesma. Ela é, de início, de desconfiança em relação ao sensível, ao corporal. O corpo é o obstáculo número um a toda a boa educação, porque sua influência sobre o espírito engendra $\circ$ erro vício. A disciplina não é, pois, simplesmente organização do trabalho e obediência ao professor, ela é também controle corporal, isto é, silêncio e domínio dos movimentos (CHARLOT, 2013, p. 237).

Sobre o que concebe em relação à autonomia e regulação, a professora P2 assim se expressa:

Regulação: trabalhamos na educação infantil com alguns documentos norteadores ECA, criança em cena, Projeto Político Pedagógico construído com toda a comunidade escolar, referencial curricular. Autonomia: o profissional da educação deve propor atividades lúdicas de forma a desenvolver a autonomia como: comer sozinho e a importância disto para a saúde bucal. Para desenvolver a autonomia, primeiramente devemos olhar a criança como um sujeito de direito e individual proporcionando as mesmas novas experiências para conhecer, explorar e imitar tudo a sua volta (P2, grifo nosso). 
Em relação ao processo de autonomia, a fala da professora (P2), apesar de anunciar a perspectiva de considerar a criança como "sujeito de direito", remete essa ideia ao campo do pedagógico quando afirma que o profissional da Educação Infantil deve propor atividades lúdicas. Ao proceder assim, não fica claro em sua fala o que realmente entende por autonomia, principalmente quando novamente retoma a ideia de imitar tudo à sua volta.

Nesse caso, a proposição de conhecer a individualidade da criança fica instrumentalizada na ideia de uma autonomia pragmática. Há, ainda, uma confusa ideia de regulação quando esta apresenta os documentos norteadores que dão suporte para a organização do trabalho pedagógico sem, contudo, explicar de fato qual a influência destes na regulação do corpo da criança e se, de fato, esses documentos participam desse momento. Sendo assim, não esclarece o sentido que emprega à concepção de autonomia.

Para a professora P4, autonomia e regulação assim se constituem: "regulação: tempo, espaço e ordem. Autonomia: independente, uma criança que aprende a cuidar de si mesma" (P4, grifos nossos).

A professora (P4) exemplifica, em frases curtas ou até mesmo por palavras-chave, a concepção que se trata. Deste modo, aproxima o sentido teórico de um corpo regulado àquele que submete a ordem, enquadrado a um espaço e um tempo subvertido às normas da escola. Por outro lado, a professora apresenta uma concepção de autonomia também instrumentalizada quando a converte na ideia de que a criança aprenda a cuidar dela mesma, particularmente em relação à higiene, e que seja independente para realizar suas atividades. Os sentidos aqui expressos não contribuem para que a criança possa ser vista como pessoa, muito menos para ter voz nos processos que a representa.

Ao entrevistar a professora Pl sobre a concepção de regulação, esta afirmou que o termo não fazia parte de suas vivências e tampouco tinha leitura, ou seja, esse termo não era familiarizado para ela. Com o objetivo de ampliar a reflexão, indagou-se, então sobre autonomia. Neste caso, a 
educadora respondeu: "construção da corporeidade, autoconhecimento, apropriação de si mesmo" (P1, grifo nosso).

Assim, percebeu-se a coerência das respostas com os estudos teóricos deste trabalho, particularmente no que diz respeito à ausência do tema em pauta no campo da formação inicial. Todavia, a professora não foi capaz de argumentar o que ela mesma entende por corporeidade, fato que a fez recair em um viés subjetivista que transfere para a própria criança o sentido do termo.

Já a Professora P5, assim discorreu sobre regulação e autonomia do corpo da criança na rotina da Educação Infantil:

Regulação: seria a definição de parâmetros para a regulação do corpo, colocar o corpo para fazer algo, como os movimentos que acontecem na rotina. Autonomia: compreendemos por autonomia os movimentos físicos e psicológicos que as crianças fazem sozinhas. As crianças engajam-se nas próprias aprendizagens, dominam novas habilidades e expõe suas opiniões e saberes na construção do conhecimento coletivo e individual (P5, grifos nossos).

Nas respostas da professora P5, particularmente no que se refere à regulação, fica explícita a presença da regulação do movimento do corpo na realização das atividades na Educação Infantil. Ao mesmo tempo, fica obscura a ideia quando menciona que a regulação está evidente no "corpo" ou "quando o coloca para fazer algo". Nessa lógica, não fica claro o que se entende por "fazer algo", fato que converte o sentido da regulação à consecução de um "parâmetro" não definido e uma certa abstração que pode ou não ser realizada. Já em relação à ideia de autonomia, a professora P5 a remete às aprendizagens e habilidades que se dão no âmbito da construção coletiva e individual. Tal perspectiva aproxima-se daquilo que Oliveira (2002) argumenta:

além de ter suas necessidades básicas reconhecidas como legítima e atendidas, recebendo cuidados de saúde e higiene, a criança deve participar de uma programação adequada de atividades. Em um clima de segurança e de liberdade, ela pode internalizar regras de comportamento e as formas de organização incluídas nas atividades propostas - como, por exemplo, os procedimentos básicos 
de ensinados, as regras de ocupação do espaço e para uso e guarda de materiais (OLIVEIRA, 2002, p. 51).

Os excertos analisados nas entrevistas abordaram diferentes concepções de autonomia e regulação. Todavia, as falas foram insuficientes para demonstrar o que, de fato, constitui uma coisa e outra em seu sentido mais amplo, mesmo quando aproximam e mencionam o corpo como objeto principal das reflexões. Contrário a essa perspectiva, este estudo defende uma concepção de corpo que se constitui da e nas relações relações sociais. Isto porque se compreende que o corpo em sua materialidade, dimensão biológica e dimensão sociocultural. Portanto, não é possível de se separar sujeito/corpo. Assim, os dados demonstram que a regulação do corpo é recortada pelo viés da ação pedagógica, pela prática, pela ação da criança, das professoras e das condições externas. Falta à compreensão das professoras uma fala que revele o sentido amplo daquilo que se nomeia como regulação ou como autonomia.

Nesse aspecto, destaca-se que o corpo da criança está imerso ao sentido da autonomia como também da regulação, por ser constituinte do mundo social. Tanto uma, quanto outra, são marcadas por processos educativos que negam as possibilidades do corpo da criança ao criarem um tipo de corpo dócil ou ainda um corpo invisibilizado.

Nessa lógica, Foucault (2014) ressalta que:

a disciplina fabrica assim corpos submissos e exercitados, corpos dóceis. A disciplina aumenta as forças do corpo lem termos econômicos de utilidade) e diminui essas mesmas forças (em termos políticos de obediência). Em uma palavra: ela dissocia o poder do corpo; faz dele por um lado uma "aptidão", uma "capacidade" que ela procura aumentar; e inverte por outro lado a relação de sujeição estrita. Se a exploração econômica separa força e o produto do trabalho, digamos que a coerção disciplinar estabelece no corpo o elo coercitivo entre uma aptidão aumentada e uma dominação acentuada (FOUCAULT, 2014, p. 135-136).

O autor argumenta a presença do corpo na história, não que o corpo tenha sido algo desinteressante, mas que as práticas sob o corpo são marcadas por disciplina e punição, ou ainda, como mecânicas de poder. 
Nas instituições de ensino aqui pesquisadas, percebe-se um corpo educado e formatado, o que se distancia totalmente das propostas apresentadas na concepção de autonomia de corpo.

Foucault (2014) compreende ainda que a proposta da educação, se conduzida pelo pressuposto da verdade, pode contribuir para que o sujeito consiga se conhecer, conhecer ou outro e modificar-se. O contrário disso, tem-se um processo que se caracteriza nas relações e situações de poder que se distanciam da ordem da autonomia, da reciprocidade e da cooperação. A regulação dos corpos tem por finalidade governar as condutas, isto é: estruturar o eventual campo de ação e conduta do outro.

As concepções das professoras sobre regulação na rotina da Educação Infantil reverberam práticas de vigilância das ações, das condutas, do pensamento, ato que pode converter-se em uma forma de poder sobre os corpos dos indivíduos, controlando seus gestos, suas atividades, sua aprendizagem, sua vida cotidiana.

No discurso das professoras entrevistadas, percebe-se uma ausência do estudo na formação inicial e continuada sobre as concepções de regulação e autonomia. A ausência do tema pode fortalecer uma ação educativa na qual a rotina da Educação Infantil pode corroborar com práticas de vigilância e de punição dos corpos na construção da corporeidade infantil. Esse risco está presente em muitas das falas ou ausências de falas e ações das profissionais da educação pesquisadas.

Portanto, os relatos das professoras e a formação teórica são duas dimensões que necessitam caminhar juntas. Todavia, o que se percebe são indicativos de elementos de autonomia física, de higiene, regulação do tempo, da ordem. O que vale ressaltar é que as falas retratam uma tentativa da assertiva das professoras sobre as concepções de autonomia e regulaçãos, mesmo que ainda de forma fragmentada e inconsistentes. 


\section{CONCEPÇÃO DE ROTINA NA EDUCAÇÃO INFANTIL}

A rotina se faz presente nas ações e organizações sociais. Se por um lado, elas são produtos culturais criados para auxiliar os homens a viverem em sociedade, a fim de organizar as atividades do cotidiano, por outro, frequentemente se torna alienada, pois o que se faz expressa ações repetidas e irrefletidas. Na Educação Infantil, a rotina é um elemento organizador da proposta do trabalho pedagógico. Numa perspectiva de crítica, considera-se que a rotina deve levar em conta o sujeito em sua totalidade.

Nas instituições de Educação Infantil, a rotina contribui para se pensar a atividade pedagógica no planejamento e na organização do espaço e do tempo. Concebe-se, portanto, que a rotina na Educação Infantil deve ser elemento organizador do trabalho e orientar a ação educativa. Sendo assim, é preciso pensar uma rotina que seja flexível e que vise a participação e a autonomia das crianças.

A rotina pode ser entendida como uma categoria que deve transitar na organização do trabalho pedagógico, a fim garantir a qualidade do atendimento às crianças. Pode também ser considerada como uma maneira de garantir tranquilidade e segurança às ações cotidianas. Assim, entende-se que as atividades de rotina não devem ser transformadas em atividades rígidas inflexíveis realizadas diariamente, mas, sim, adequar as atividades diárias não ao ritmo das crianças e não da instituição e do professor. Claro que a instituição e o trabalho do professor também precisam ser considerados. Todavia, o centro do planejamento pedagógico deve ser sempre o melhor interesse da aprendizagem e do desenvolvimento das crianças. Portanto, a rotina pode e deve sofrer modificações e inovações quantas vezes forem necessárias durante o ano letivo.

Nesse sentido, Barbosa (2006) afirma que:

a rotina é compreendida como uma categoria pedagógica da Educação Infantil que opera como uma estrutura básica organizadora da vida cotidiana diária em certo tipo de espaço social, creches ou pré-escola. Devem fazer parte da rotina todas as 
atividades recorrentes ou reiterativas na vida cotidiana coletiva, mas nem por isso precisam ser repetitivas (BARBOSA, 2006, p. 201).

A proposta da rotina na Educação Infantil deve ser planejada, flexível nas relações criança e criança, criança e adultos, criança com o espaço e o tempo, necessidades individuais e coletivas, o ensino e as particularidades de cada criança. A organização do tempo e do espaço educacional está interligada às propostas pedagógicas para o desenvolvimento integral da criança. É necessário realçar que a rotina nas instituições de Educação Infantil parece obedecer a uma lógica temporal, como: tempo de comer, tempo do banho, tempo de brincar, tempo de aprender. Estes tempos devem ser considerados como atos educativos que não podem orientar-se por propostas que fragmentem a criança em tempos e ações particularizadas.

Nesse viés, este estudo entendeu a necessidade de se escutar as professoras sobre a concepção de rotina e ação educativa, por acreditar serem sujeitos que organizam esse contexto. Sobre o tema, a professora P3 argumentou:

Rotina: a rotina da criança envolve o corpo e o movimento, considerando o aspecto cognitivo, motor, social. Ação educativa: a prática pedagógica com as crianças se dá através de projetos, que são elaboradas a partir do interesse das crianças, os quais são constatados através das observações realizadas durante os diversos momentos da rotina no CMEl. Durante os projetos trabalhamos o corpo, o cuidado, higiene, o movimento, conhecimento científico (P3).

Não há, na fala da professora, algo que esclareça a concepção de rotina. Pelo contrário, ao citar o corpo e o movimento ela acaba por subsumir o tema e convertê-lo no âmbito das dimensões cognitiva, motor e social. Ao tratar do sentido do corpo, não explorou os significados de espaço, tempo e organização do trabalho pedagógico, mas, ao contrário, atribuiu à essas dimensões algo quase correlato à constituição do próprio corpo. Já em relação à ação educativa, aproxima essa ideia às articulações entre prática pedagógica e projetos, por serem propostas que integram a 
criança nas relações sociais e de aprendizagem como um todo, visando ao desenvolvimento integral da criança.

$\mathrm{Na}$ conceituação de rotina na Educação Infantil, os sujeitos a classificam a partir de diversos parâmetros, fazendo-se necessário seu planejamento diário, organizando a execução de atividades e funcionando como norteador do tempo pedagógico. Cavasin (2008) lembra que a rotina deve ser estruturante, uma bússola na orientação da ação pedagógica. Portanto, afirma que:

a rotina estruturante diferencia-se da mecânica por ser planejada, por pertencer à proposta pedagógica da instituição, por respeitar a criança e seus ritmos. Ela também dá mais liberdade ao professor para lidar com $O$ inesperado, sem cair no espontaneísmo pedagógico; há uma intencionalidade na ação, tornando-se o professor um mediador de situações significativas que auxiliam no desenvolvimento das crianças (CAVASIN, 2008, p. 61).

Percebe-se, portanto, a necessidade e a importância de se considerar o tempo para o planejamento não só das atividades, mas também, das brincadeiras, inserindo-as na rotina. Ao mesmo tempo, o professor deve atentar-se para a diversidade de materiais a serem disponibilizados para as crianças, considerando as idades de cada uma e o momento de arrumação para propor acessibilidade e dar-lhes autonomia para manuseálos.

Sobre a fala da professora (P4), destaca-se a exposição em forma de palavras-chave: "rotina: tempo, espaço e atividade. Ação educativa: metodologias, objetivos, registros de aprendizagem" (P4, grifos nossos). As repostas demonstram fragmentação teórica, principalmente quando limita a rotina ao espaço, ao tempo e à atividade. Isto se dá sem contextualização sobre qual o real papel desses conceitos no sentido da rotina, ou seja, como se dá a função de ambos na realização das atividades. Neste sentido, acontece também a limitação da ação educativa em metodologias e registros de aprendizagem. Não explicita, ainda, o que poderia convergir para uma rotina e ação educativa que fosse reveladora do trabalho pedagógico educativo, incluindo as particularidades de cada criança, 
como também considerando a bagagem que chega até a instituição. Tais considerações poderiam conduzir à formação da autonomia da criança.

De acordo com Batista (1998), é necessário romper com a concepção de rotina como algo que determina o tempo e obedece a uma lógica escolar, focada na sequência cronológica, na relação do adulto ao transmitir o tempo da criança. Nesta ação, fica explícita uma centralidade no professor controlador, que se preocupa em obedecer à rotina estabelecida sem considerar as condições e necessidades da criança.

Segundo Barbosa (2006, p.37): "[...] as rotinas podem ser vistas como produtos culturais criados, produzindo e reproduzidos no dia a dia, tendo como objetivo a organização da cotidianidade". Portanto, é preciso repensar sobre o tempo, o espaço e suas proposições nas instituições de Educação Infnatil reconhecendo os ambientes heterogêneos, plurais, ricos em aprendizagens, brincadeiras, fantasias e sonhos com vistas a promover o desenvolvimento integral das crianças.

Horn (2004), a partir de seus estudos acerca desse tema, esclarece que:

as escolas de educação infantil têm na organização dos ambientes uma parte importante de sua proposta pedagógica. Ela traduz as concepções de criança, de educação, de ensino e aprendizagem, bem como uma visão de mundo e de ser humano do educador que atua nesse cenário. Portanto, qualquer professor tem, na realidade, uma concepção pedagógica explicitada no modo como planeja suas aulas, na maneira como se relaciona com as crianças, na forma como organiza seus espaços na sala de aula. (...) Conforme Farias (1998), a pedagogia se faz no espaço realidade e o espaço, por sua vez, consolida a pedagogia. Na realidade, ele é o retrato da relação pedagógica estabelecida entre crianças e professor (HORN, 2004, p. 61).

A organização dos espaços e tempos na Educação Infantil deve ser atraente e estimulante e estar a favor do desenvolvimento e aprendizado das crianças, com 0 intuito de propiciar-lhes experiências novas e diversificadas, nas quais possam se movimentar e interagir com objetos e seus pares.

Na entrevista realizada com a Professora P2, tem-se o seguinte sobre essas concepções: 
Rotina: a rotina é muito importante, possibilitando à criança segurança e domínio do espaço e do tempo, mas essa rotina não deve ser engessada 0 professor deve sempre redirecionar 0 planejamento para atender as necessidades das crianças pela qual trabalha. Ação educativa: ação educativa na Educação Infantil objetiva trabalhar com 0 cuidar e educar, o profissional da educação deve ter um olhar observador para planejar atividades lúdicas de forma a desenvolver a criança em seu todo [cognitivo, afetivo, social, motor e linguístico] (P2, grifo nosso).

As respostas dadas indicam elementos que contribuem com 0 trabalho educativo nas instituições da Educação Infantil, principalmente na ideia de planejamento. Deste modo, pode-se afirmar o planejamento como mediador da ação educativa, uma vez que ele deve considerar as necessidades da criança, sua presença no mundo e sua formação como sujeito humano e histórico.

Assim, a rotina das instituições da Educação Infantil deve reconhecer a multiplicidade dos tempos dos sujeitos envolvidos, os espaços (internos e externos das instituições) e ambientes. Neste sentido, a rotina se constitui a partir de um processo dinâmico, social, histórico e mutável a todo o momento. Deve levar em conta as particularidades dos sujeitos envolvidos na construção do conhecimento. Pensar a criança na rotina e nas ações educativas da Educação Infantil, principalmente na organização do espaço, implica considerar as especificidades de cada uma, já que a criança é: um "sujeito histórico e de direitos. Ela se desenvolve nas interações, relações e práticas cotidianas a ela disponibilizadas e por ela estabelecidas com os adultos e crianças de diferentes idades nos grupos e contexto culturais nas quais se insere" (OLIVEIRA, 2010, p. 05).

Ainda sobre as entrevistas que versaram sobre o tema rotina e ação educativa, a professora $\mathrm{P} 1$ respondeu:

Rotina: é o que organiza, estrutura e sistematiza o trabalho, devendo ser flexível e democrático. Ação educativa: são as ações que acontecem nos diferentes tempos e espaços da instituição de educação infantil de maneira planejada/intencional ( $\mathrm{Pl}$, grifos nossos). 
Tal discurso aproxima-se da entrevista concedida pela professora P5 sobre concepções de rotina e ação educativa na educação infantil, sendo:

Rotina: é a organização das ações estabelecidas de acordo com orientações da SME, como também de documentos norteadores, sendo organizadas as necessidades e especificidades das crianças, sendo contudo, flexível de acordo com as singularidades de cada criança. Ação educativa: a ação educativa sugere que pensemos os nossos processos formativos em âmbito subjetivo e também coletivamente. Nesse sentido, afirmamos a presença constante da intencionalidade sem prescindir da intrínseca relação entre o educar e o cuidar, entendendo que toda ação educativa pressupõe aquilo que é peculiar, a natureza pedagógica [...] (P5, grifos nossos).

Diante do exposto nas falas das P1 e P5, percebem-se elementos da intencionalidade ao propor atividades para as crianças, objetivando conhecê-las para direcionar uma formação social e educacional. Evidenciase, ainda, a preocupação em organizar os espaços e tempos, declarando as particularidades e necessidade das crianças. As falas retratam uma postura flexível nas mediações e intervenções pedagógicas, nas quais o sujeito criança ocupa um alugar de construtor de aprendizagem. Neste aspecto, aponta-se o quanto é importante o papel do outro na constituição do eu, como também no desenvolvimento da aprendizagem, já que ambos são construídos/constituídos ao longo da história.

Destarte, as concepções aqui abordadas apresentam os sujeitos envolvidos na pesquisa, ora na escuta e na observação, ora somente na observação, por demarcar este lugar da instituição da Educação Infantil como campo fértil para a formação da identidade da criança. Essa se dá de maneira dialética e em processos de conflitos e tensões. Sendo assim, o tema em estudo precisa ser aprofundado na formação inicial e continuada dos professores, a fim de contribuir também para o fortalecimento de uma identidade docente mais humana, acadêmica e profissional.

\section{A COMPREENSÃO DO ATO EDUCATIVO}

As atividades desenvolvidas na Educação Infantil devem ser planejadas e articular os aspectos da ação educativa e pedagógica que 
visem a formação da criança em uma perspectiva integral. Tendo como análise a perspectiva histórico-cultural, o ato educativo objetiva o processo de humanização, sendo que o sujeito-homem se apropria daquilo que the é externo nas relações culturais e nela se afirma. Nesta perspectiva, Mello (2007) discorre:

com a teoria histórico-cultural, aprendemos a perceber que cada criança aprende a ser um ser humano. O que a natureza the provê no nascimento é condição necessária, mas não basta para mover o seu desenvolvimento. É preciso se apropriar da experiência humana criada e acumulada ao longo da história da sociedade (p. 88).

Segundo o documento "Infância e Crianças em Cena: por uma Política de Educação Infantil para a Rede Municipal de Educação de Goiânia 2014", "as ações educativas estão presentes nos diferentes tempos e espaços que envolvem as trocas socioculturais". A presença das ações educativas se aproxima da ação pedagógica no seguinte sentido: "as relações humanas, as trocas sociais, os afetos o cuidado de si e do outro e a subjetividade, bem como a individualidade de cada criança, são aspectos que fazem da ação educativa uma dimensão articulada á ação pedagógica" (GOIÂNIA, 2014, p. 125).

Toma-se, aqui, a voz e a compreensão das professoras pesquisadas sobre o banho e o sono como atividades inerentes ao ato educativo na Educação Infantil. Como produção cultural e pedagógica, as atividades que ocorrem neste espaço educativo precisam ser vivenciadas e apreendidas pelas crianças, e também pelas professoras, uma vez que é na e pela cultura que se tornam sujeitos humanos.

Ao indagar as professoras sobre em que medida o banho e o sono se constituem como ato educativo, as respostas foram:

na medida em que o banho for planejado, preparado e realizado para o desenvolvimento da autonomia da criança, na interação adulto-criança e criança-criança. Sono: o momento do sono deve ser respeitado e não imposto, respeitando o ritmo de cada criança, algumas dormem com mais facilidade, outras necessitam de carinho e atenção (P3, grifos nossos). 
O banho denominado como banho refrescante e ao mesmo tempo pedagógico neste momento tem contato direto com a criança, não só trabalhando o corpo e sua função ou como de se lavá-lo, mas é também um momento que questionamos e instigamos a criança, para falar um pouco sobre ela, o que sente, o que sabe, o que quer aprender e a partir deste diálogo vamos direcionando nosso fazer pedagógico. Sono: o sono, entendo que nesta faixa etária é muito importante para $o$ desenvolvimento da criança e neste momento deitamos com ela, fazemos carinho, conversamos, colocamos músicas. Proporcionamos momentos pedagógicos de aconchego, afetividade e individualidade ( $\mathrm{P} 2$, grifos nossos).

Banho: onde as crianças aprendem sobre a higiene, a cuidarem do próprio corpo. Sono: trabalho o sentido da audição, a música como forma de terapia e descanso (P4, grifos nossos).

O banho é um momento privilegiado de contato direto com a criança. No momento do banho, além de orientar sobre os cuidados com a higiene do corpo, nomeá-la corretamente, serve ainda como um momento em que se encontra um número menor de crianças, o que possibilita maior diálogo. Poder ouvir, escutar... Algumas crianças apresentavam esse ano, dificuldade na linguagem e essa dificuldade foram trabalhadas principalmente no horário do banho, quando ao repassar orientações podia "ouvir" melhor o que faltavam. Sono: o sono deve ser reconhecido como um momento necessário para o descanso e desenvolvimento do corpo. Uma pausa para brincar mais e com mais saúde ( $\mathrm{Pl}$, grifos nossos).

Banho: Na medida em que a criança entra em contato com próprio corpo, que vai se constituindo significante para ela, através de orientação quanto ao aspecto biológico, discriminando corretamente as partes do corpo que impõe sobre a cultura que diverge de um indivíduo para outro, de uma crença para outra e no respeito a essas diferenças se apropriando do próprio corpo e da sua condição humana.

Sono: Na medida em que a criança tem o poder de decidir se quer ou não repousar, onde deseja repousar, esse poder de escolha a torna cidadã que pensa, que decidi, Ihe dá 0 direito de ser respeitada em suas vontades e ao mesmo tempo o dever de respeitar a vontade dos outros (P5, grifos nossos).

A professora P4 direcionou sua fala no sentido da higiene do corpo e não reconheceu o banho e o sono como atividades educativas. Da mesma forma, não explorou nenhuma outra possibilidade decorrente destas práticas. Já as professoras P1 e P2 partiram das respostas destacando aspectos como diálogo, orientação das crianças, processo de escuta e reconhecimento do corpo. As professoras P5 e P3 relatam sobre autonomia e relações com outras crianças, como também com a professora. Pautou-se, 
ainda, a inserção da cultura na determinação do corpo da criança, ressaltando a importância de se conhecer e respeitar as diferenças.

Em relação ao sono, chamou a atenção desta pesquisa a fala da professora P4, quando menciona o banho em contextos de "terapia" no ato educativo, como também reafirma sua importância para os sentidos da audição. Essa fala reforça a ideia de fragmentação acerca da compreensão do corpo da criança, ainda mais quando se compreende que o ambiente da sala de aula da Educação Infantil tem um viés diferente da proposta de terapia propriamente dita. A proposta pedagógica visa a formação da autonomia, emancipação do sujeito no ambiente educacional.

O ato do banho na Educação Infantil devem expressar uma intencionalidade pedagógica para além do cuidar do corpo. Deve permitir que a criança se conheça e fortaleça seus processos de autonomia. Logo, o banho pode e deve existir em uma relação dialética entre aprendizagem e desenvolvimento. Para Vygotsky (2007):

aprendizagem não é desenvolvimento; entretanto, o aprendizado adequadamente organizado resulta em desenvolvimento mental e põe em movimento vários processos de desenvolvimento que, de outra forma, seriam impossíveis de acontecer. Assim, o aprendizado é um aspecto necessário e universal do processo de desenvolvimento das funções psicológicas culturalmente organizadas e especificamente humanas (p. 103).

Outrossim, os processos de construção da autonomia só se dão na relação do sujeito com o conhecimento, ou seja, o sujeito passa a ser autônomo quando, em atividade, elabora e produz sentidos e significados sobre esta ação.

As falas das professoras demonstram uma certa "autonomia" ditada por práticas pedagógicas. É possível apreender em suas falas uma autonomia regulada que está ancorada na dependência da criança em relação ao adulto. Esta postura produz um tipo de relação na qual as crianças esperam sempre que os adultos Ihes digam o que fazer e como fazer no banho ou no sono. Contrário a isso, reforça-se aqui a ideia de que a 
construção e constituição do corpo se dão nas inter-relações, no ambiente da instituição de ensino, no suporte teórico que orienta a ação, na prática educativa intencionalizada e nos significados produzidos em diferentes contextos sociais. Todavia, são mediações como curiosidades, conversas, autonomia, organização do espaço, dentre outras, que possibilitam à criança o entendimento sobre como se constitui, de fato, o sentido do corpo nas relações sociais. Sendo assim, o banho é um momento pedagógico propício para se conhecer e cuidar do próprio corpo, conhecer e respeitar as diferenças.

O documento das Diretrizes Curriculares Nacionais da Educação Infantil (BRASIL, 2009) propõe pensar currículo nesta etapa da educação como "práticas educacionais organizadas em torno do conhecimento e em meio às relações sociais que se travam nos espaços institucionais, e que afetam a construção de identidade das crianças". Salienta-se que a identidade da criança se dá na sua totalidade. Isso implica dizer que não se limita à mente, mas sim, mente e corpo como unidades integradas, sendo a corporeidade a possibilidade de expressão dessa identidade. Deste modo, a organização do currículo para a Educação Infantil precisa considerar os momentos de sono e descanso na organização das rotinas da creche e préescola.

A organização e o planejamento das rotinas para o momento de sono na Educação Infantil estão interligados à concepção de sujeito que se tem. Quando concebemos a criança como sujeito integral, esta organização consistirá em considerar suas especificidades e necessidades individuais dentro do coletivo.

Segundo Rosseti-Ferreira (2005),

o momento do sono muitas vezes é percebido como um castigo para as crianças e para os educadores. Quem trabalha em creches com crianças até mais ou menos quatro anos sabe como é importante o soninho durante o dia e ao quanto, muitas vezes, é desgastante chegar até ele (p. 143). 
Durante as entrevistas, também se questionou às professoras sobre como o banho e o sono eram planejados no ato educativo e executados na rotina da Educação Infantil. O intuito era saber como se davam os processos de desenvolvimento da autonomia nessas atividades, se atentando para o tempo estabelecido para cada um dos momentos.

A professora Pl considera que o banho e o sono: "são inseridos normalmente no planejamento, tendo em vista que na Educação Infantil, tudo é pedagógico" (Pl, grifo nosso). Todavia, a professora Pl não explicita o que, de fato, constitui o sentido do que ela nomeia por "pedagógico", "intencionalidade" e "planejamento". Diz também que autonomia se dá em "atos simples como se despir ou vestir, cuidar do próprio material de uso pessoal. Nessas atividades, as crianças tomam consciência de si mesmas [...]". Destaca-se, de sua fala, que o processo de autonomia se dá por meio de "manuseio" de materiais, fato que traria às crianças "consciências de si mesmas". Isso implica refletir que a tomada de consciência ou autonomia só é possível mediante relação da criança com aquilo que é externo. Quanto ao tempo, ela menciona:

todas as crianças demoram a dormir, mas, conseguem dormir, porém não teve necessidade de oferecer outra atividade para as crianças que não dormem, pois as mesmas ficam quietinha deitadas no colchão na sala de aula. Respeitamos o tempo da criança para dormir, o período do sono acontece em torno de duas horas diária ( $\mathrm{Pl}$, grifos nossos).

Para a professora P2, o banho e o sono: "são muito bem planejadas, para isso o profissional deve ter um olhar observador e se questionar, para sempre redirecionar 0 planejamento, para que estes momentos sejam de aprendizagem" (P2, grifos nossos).

Sobre as atividades no desenvolvimento da autonomia, a professora P2 respondeu: "as crianças neste momento conseguem controlar e identificar seu corpo, podendo expressar seus sentimentos. As duas atividades precisam ser bem planejadas para garantir a aprendizagem" (P2, grifo nosso). 
A professora discorre, ainda, acerca do que entende por corpo:

- corpo da criança de cinco anos de idade consegue expressar seus sentimentos nas atividades do banho e do sono, importante destacar que os sentimentos precisam ser escutados e vistos com olhar de formadores de sujeitos autônomos ( $P 2$, grifos nossos).

Nesse caso, o sentido de autonomia não fica claro. Nota-se que a criança está regulada por uma proposta da instituição, melhor dizendo, do professor que se encontra controlando sua identidade corporal. A professora P2 disse que o tempo que as crianças dormem é de aproximadamente 3 horas diárias e pontuou ainda que as que não dormem ficam com outra profissional. Da mesma forma, traduz uma ideia de expressão corporal cronológica datada àquelas que se inscrevem com 5 anos. $\mathrm{E}$ as demais? $\mathrm{E}$ as menores? Não podem ou não conseguem expressar seus sentimentos por meio do corpo?

Já a professora P5, no que diz respeito ao planejamento do banho e do sono, realça que:

\begin{abstract}
essas duas atividades são planejadas de modo a atender as necessidades de segurança, aconchego, afeto, higienização, repouso e privacidade, bem como, promover a socialização, autonomia, expressão, descoberta e exploração por meio da experimentação. Nossa Instituição não possui infraestrutura que permita banhos individuais por grupos de crianças, nesse sentido, buscamos organizar esse momento de modo que ocorra com tranquilidade, naturalidade e que seja agradável à criança. Nosso banheiro é dividido em três chuveiros, sendo cada chuveiro destinado a um agrupamento, no caso do pavilhão observado, agrupamentos D, E, F. Dessa forma, o banho acontece simultaneamente entre os agrupamentos citados. As professoras e auxiliares agem como mediadoras nesse processo interagindo com as crianças, respeitando as especificidades e individualidades de cada uma, orientando sobre os procedimentos peculiares a esse momento.
\end{abstract}

No relato da professora P5, pode-se perceber que a prática do banho não garante a privacidade das crianças, uma vez que na instituição existe apenas um único banheiro, com três chuveiros e que atende a três agrupamentos simultaneamente. Nesta ótica, percebe-se que a privacidade 
da criança se anula para dar lugar ao número de crianças e ao espaço limitado.

A professora (P3) também se manifestou em relação ao planejamento das atividades do banho e do sono:

na rotina do trabalho essas duas atividades são planejadas semanal, sempre com um profissional para auxiliar e orientar as crianças. No momento do banho, a regente fica na sala, auxiliando as crianças para que as mesmas adquiram autonomia e consigam despir e vestir sozinhos. A auxiliar de atividades educativas leva um grupo de crianças para o banho e auxiliá-la na higienização pessoal. Para evitar o tempo de espera são oferecidas às crianças um filme ou desenho. Para o sono propicia um ambiente aconchegante, fechamos as cortinas, ligamos o ventilador e sentamos próximo das crianças (P3, grifos nossos).

A professora apresenta uma separação dos papéis na atividade com as crianças, sendo que a auxiliar fica responsável pelo ato do banho, enquanto a professora acompanha as crianças na organização dos materiais e vestimentas. Assim, quando a professora foi indagada sobre o planejamento, respondeu que o apresenta para a auxiliar educativa. Já a professora (P3) respondeu que as crianças dormem aproximadamente duas horas por dia e as que não querem ficam deitadas sem dormir. Disse que o sono as crianças ficam com a auxiliar da sala. Relata que ela e a auxiliar sentam próximas às crianças para fazer carinho na cabeça ou nas costas, ao mesmo tempo em que reafirmam, às crianças, que elas precisam descansar. A resposta da professora permite perceber uma regulação do corpo da criança especificamente durante o sono, assim como sua ausência durante $O$ ato do banho. $O$ ato de coçar a cabeça e as costas tem uma função objetiva: fazer com que as crianças durmam.

Conforme Foucault (2005),

nesse conjunto de alinhamentos obrigatórios, cada aluno segundo sua idade, seus desempenhos, seu comportamento, ocupa ora uma fila, ora outra; ele se desloca o tempo todo numa série de casas; [...] que marcam uma hierarquia do saber ou das capacidades (p. 125). 
As falas das professoras corroboram com a perpectiva salientada por Foucault (2005), quando nos permitem perceber que a organização do espaço nas escolas é uma maneira que determina o lugar a cada um nas relações sociais. O professor fica na administração do tempo, como também organiza a divisão do espaço. Isto possibilita a vigilância, o controle e a recompensa. Quando a professora (P1) menciona que a criança, mesmo "não estando com sono, fica deitada e quietinha", percebe-se que a identidade corporal da criança está regulada e controlada por uma rotina marcada pela instituição e pelo adulto.

Da mesma forma, indagou-se à professora P4 sobre o planejamento nas atividades do banho e do sono. A professora respondeu: "no banho as crianças são estimuladas a terem autonomia, a cuidarem dos seus objetos" (P4, grifo nosso). Ela especifica a autonomia no sentido do cuidar dos objetos. Neste caso, o corpo não aparece nas dimensões que o cercam: movimento, desenvolvimento emocional, desenvolvimento cognitivo. Quanto ao sono, argumenta: "no sono as crianças dormem nos colchonetes e quando precisam a professora dá carinho para a criança ter um sono tranquilo" (P4, grifo nosso).

As falas da (P4) não explicitam o que implica a autonomia em relação à atividade e em relação à presença do corpo. Da mesma forma, não aparece o planejamento em ambas as atividades. A professora menciona autonomia quando as crianças cuidam dos objetos e trocam de roupas sozinhas. Em relação ao tempo, "O sono acontece duas horas, quando algumas crianças não querem dormir, entregamos livros ou brinquedos". Em suas falas a professora deixa claro que esses brinquedos são entregues para crianças, porém, não podem fazer barulho.

Para Corsino (2009, p. 119), "o que dá sentido ao cotidiano das crianças é justamente a possibilidade de estabelecer relações, de participarem de processos que se inter-relacionam em que uma atividade se desdobra em outra de forma integrada". Neste caso, os estudos da autora contribuem para repensarmos as práticas docentes aqui explicitadas e 
apontarmos outras perspectivas pedagógicas para o trabalho na Educação Infantil.

\section{CONSIDERAÇÕES FINAIS}

Este trabalho sinaliza para algumas preocupações como a evidência de uma pedagogia do disciplinamento dos corpos. Essa pedagogia foi marcada por processos de regulação, administração e gestão dos tempos, espaços, práticas e corpos. Todavia, uma das questões que mais chamou atenção neste estudo diz respeito à forma como as crianças tiveram seus corpos disciplinados nas atividades do banho e do sono. Nestes cenários, foram explícitas as formas como as crianças se relacionavam com seus corpos, bem como seus modos de expressão e comunicação, em uma relação estabelecida sob a regulação dos adultos, como também da organização da rotina.

Na contramão dos processos regulatórios, foi possível, durante as observações e os registros, ver também como as crianças expressavam sua dimensão corporal nos momentos do banho e do sono. Nestes momentos, brincavam com a água, a espuma do sabão, a roupa, o colchão, observando os ventilados com o lençol no rosto. Na maioria das vezes, elas eram reprimidas pelo poder do adulto que as impediam de ficar acordadas, manusear os instrumentos durante o banho, enfim, os professores buscavam manter o controle/disciplina do corpo.

Os resultados deste trabalho também evidenciam a dicotomia acentuada pela ruptura ou indefinição do trabalho efetivo das professoras e das auxiliares e suas condições objetivas de trabalho. Da mesma forma, ressaltam a importância de se considerar os materiais propostos para a realização das atividades observadas e as condições de trabalho, sendo que os espaços físicos das instituições e o manusear dos materiais não contribuíram para a constituição da formação da identidade corporal por serem mecanismos controlados. Esta reflexão é importante, uma vez que não se quer aqui culpabilizar as professoras por nenhuma prática. Pelo contrário, reafirma-se, aqui, que muito do que foi observado como "prática 
incoerente" com o que se espera no trato do tema devem-se, sobremaneira, às condições de trabalho a que essas profissionais estavam expostas (banheiros inadequados, salas improvisadas para o sono etc.) Todavia, se por um lado as condições não contribuíram para um trabalho de qualidade, por outro, a prática observada confirmou a recorrência da participação convertida em uma norma ou em instrumentalização das ações. Isso só se evidenciou porque esteve clara a dicotomização entre cuidar e educar em todo o processo educativo que implicava considerar a problemática deste estudo, que muitas vezes, é ausente da formação inicial e continuada. Por fim, espera-se que este trabalho seja mais um instrumento na luta por uma educação da infância comprometida com o sujeito criança em uma perspectiva crítica e emancipatória, bem como, para a consolidação de uma política pública comprometida com a qualidade socialmente referenciada às crianças brasileiras.

\section{REFERÊNCIAS}

BARBOSA, M. C. S. Por amor e por força: rotinas na Educação Infantil. Porto Alegre: ARTMED, 2006.

BATISTA, R. A rotina no dia a dia da creche: entre o proposto e o vivido. 1998. 175f. Dissertação (Mestrado em Educação) - Universidade Federal de Santa Catarina, Florianópolis, 1998.

BRASIL. Ministério da Educação. Secretária de Educação Básica. Diretrizes Curriculares Nacionais para a Educação Infantil. Braślia: MEC, SEB, 2009.

CAVASIN, R. F. A Organização das Rotinas com Crianças de 0 a 3 Anos e sua Relação com o Referencial Curricular Nacional Para Educação Infantil RCNEl. Joaçaba, SC. Dissertação (Mestrado em Educação) - Universidade do Oeste de Santa Catarina, Joaçaba, 2008.

CHARLOT, B. A mistificação pedagógica. Rio de Janeiro: Zahar, 2013.

CORSINO, P. Considerações sobre o planejamento na Educação Infantil. In: CORSINO, P. Educação Infantil: cotidiano e políticas. Campinas: Autores Associados. 2009.

FOUCAULT, M. Vigiar e Punir: nascimento da prisão. Trad. 42. ed. Petrópolis, RJ: Vozes, 2014. 
FOUCAULT, M. História da Sexualidade 1: A Vontade de Saber. 17. ed. Rio de Janeiro. Graal, 2005.

GOIÂNIA. Secretaria Municipal de Educação. Infâncias e crianças em cena: por uma política de Educação Infantil para a Rede Municipal de Educação de Goiânia. Goiânia, 2014.

HORN, M. da G. S. Sabores, cores, sons, aromas. A organização dos espaços na Educação Infantil. Porto Alegre: Artmed, 2004.

MELLO, S. A. A escola de Vygotsky. In: CARRARA, K. (Org.). Introdução à psicologia da educação: seis abordagens. São Paulo: Avercamp, 2007.

OLIVEIRA, Z. M. R. O currículo na Educação Infantil: o que propõem as novas diretrizes nacionais? In: I SEMINÁRIO NACIONAL CURRÍCULO EM MOVIMENTO - perspectivas atuais, 2012, Belo Horizonte. Anais... Belo Horizonte, 2010.

OLIVEIRA, Z. M. R. Educação Infantil: fundamentos e métodos. São Paulo: Cortez, 2002.

ROSSETTI-FERREIRA, M. C. Nana, neném... zzzzzzz. In: Os fazeres na educação infantil. São Paulo: Cortez, 2005.

SIQUEIRA, R. M. Por uma leitura crítica das concepções de infância e criança. 2011. Tese (Doutorado em Educação) Universidade Federal de Goiás. Goiânia, 2011.

VYGOTSKY, L. S. A formação social da mente. 7. ed. São Paulo: Martins Fontes, 2007.

Recebido em: 15 de fevereiro de 2019 Aprovado em: 03 de julho de 2019 